\title{
Service Life Extension of the ISS Propulsion System Elements
}

\author{
Ulhas Kamath $^{*}$ and Gregory Grant ${ }^{\dagger}$ \\ The Boeing Company, Houston, TX 77059 \\ Sergei Kuznetsov ${ }^{\ddagger}$ and Sergey Shaevich ${ }^{\S}$ \\ Khrunichev Space Center, Moscow 107996 \\ and \\ Victor Spencer ${ }^{* *}$ \\ NASA Lyndon B. Johnson Space Center, Houston, TX 77058
}

\begin{abstract}
The International Space Station (ISS) is a result of international collaboration in building a sophisticated laboratory of an unprecedented scale in Low Earth Orbit. After a complex assembly sequence spanning over a decade, some of the early modules launched at the beginning of the program would reach the end of their certified lives, while the newer modules were just being commissioned into operation. To maximize the return on global investments in this one-of-a-kind orbiting platform that was initially conceived for a service life until 2016, it is essential for the cutting edge research on ISS to continue as long as the station can be sustained safely in orbit. ISS Program is assessing individual modules in detail to extend the service life of the ISS to 2024, and possibly to 2028. Without life extension, Functional Cargo Block (known by its Russian acronym as FGB) and the Service Module (SM), two of the early modules on the Russian Segment, would reach the end of their certified lives in 2013 and 2015 respectively. Both FGB and SM are critical for the propulsive function of the ISS. This paper describes the approach used for the service life extension of the FGB propulsion system. Also presented is an overview of the system description along with the process adopted for developing the life test plans based on considerations of system failure modes, fault tolerance and safety provisions. Tests and analyses performed, important findings and life estimates are summarized. Based on the life extension data, FGB propulsion system, in general, is considered ready for a service life until 2028.
\end{abstract}

\section{Nomenclature}

$\begin{array}{ll}F & =\text { probability of failure } \\ R & =\text { reliability } \\ \lambda & =\text { failure rate } \\ t & =\text { time } \\ \beta & =\text { shape factor } \\ \eta & =\text { scale factor } \\ t_{b d} & =\text { time-to-breakdown } \\ t_{T} & =\text { life demonstrated by test } \\ t_{L} & =\text { service life } \\ \alpha & =\text { acceleration factor }\end{array}$

\footnotetext{
* Senior Technical Lead, Propulsion Division, Boeing Defense, Space \& Security, MC HB5-30

$\dagger$ Project Manager, ISS Logistics Services, Boeing Defense, Space \& Security, MC HB5-30

$\$$ Division K02 Chief, Khrunichev State Research \& Production Space Center

$\S$ Program Director, Khrunichev State Research \& Production Space Center

** ISS Propulsion System Manager, Propulsion and Power Division, EP4. AIAA Member 
$T_{T} \quad=$ temperature during accelerated test, $\mathrm{K}$

$T_{L} \quad=$ average temperature during service life, $\mathrm{K}$

\section{Introduction}

$\mathrm{T}$ he International Space Station (ISS) is the largest space project to date and the most complex international scientific project in history. Built under a joint collaboration of 16 countries, the ISS is the largest international peacetime endeavor in human history. With significant accomplishments in the areas of human health, telemedicine, education and Earth observations, the ISS has been enhancing the quality of life on Earth, while transforming the utilization and exploration of space to become safer and more affordable. In order to maximize the benefits of the global investments in the ISS, it is essential to continue experiments on this unique platform by allowing opportunities to a large number of researchers to have new theories tested in microgravity, thereby increasing the odds of scientific breakthroughs that could benefit the humanity.

Weighing almost a million pounds, the ISS is about four times as large as the Russian space station Mir and about five times as large as the U.S. Skylab. Constructed over a span of more than a decade with the help of over 100 space flights, elements and modules of the ISS provide more research space than any spacecraft ever built. Originally envisaged for a service life of fifteen years, this Earth orbiting laboratory has been in orbit since 1998. Some elements that have been launched later in the assembly sequence were not yet built when the first elements were placed in orbit. This meant that some of the early modules that were launched at the inception of the program would already be at the end of their design life when the ISS was finally ready and operational.

For instance, Functional Cargo Block (known by its Russian acronym as FGB) and the Service Module (SM), which were launched in November 1998 and July 2000, would reach the end of their original certified lives in 2013 and 2015 respectively. Both FGB and SM are critical for the propulsive function of the ISS. The propulsion system operates beginning with the launch of station elements into orbit until the final deorbit; its service life determines the service life of the station overall.

The ISS Propulsion System, managed by the Russian Segment, makes use of Unsymmetrical Dimethylhydrazine (UDMH) as fuel and Nitrogen Tetroxide (NTO) as oxidizer. With over six tons of propellant storage capacity, FGB serves as a large reservoir of ISS propellants. The Service Module (SM) provides onboard capacity for an additional 860 kilograms of ISS propellants. In addition, visiting vehicles such as the Russian Progress and European Automated Transfer Vehicle (ATV) replenish the FGB and SM propellants on a regular basis. With a fully operational propulsion system, equipped with central computers and a network of propellant lines, components and thrusters, the SM manages the integrated ISS propulsive control.

After the Service Module was attached to the aft docking port of the FGB, the primary responsibility of the FGB has been to provide skip cycle propellant storage capacity, necessary to allow the ISS to remain in orbit for up to one year without logistics support from the Earth in the event of missed logistics opportunities.

It is possible to perform ISS attitude and altitude maintenance with the help of propellants manifested on visiting vehicles, without dipping into the onboard reserves. Over $90 \%$ of the propellants consumed in the last 15+ years of ISS existence were supplied by the visiting vehicles ${ }^{1}$. However, retaining access to the FGB propellant reserve is critical for the success of skip cycle survival and a safe deorbit of the ISS. Nominally at the end of the ISS life or in an unrecoverable

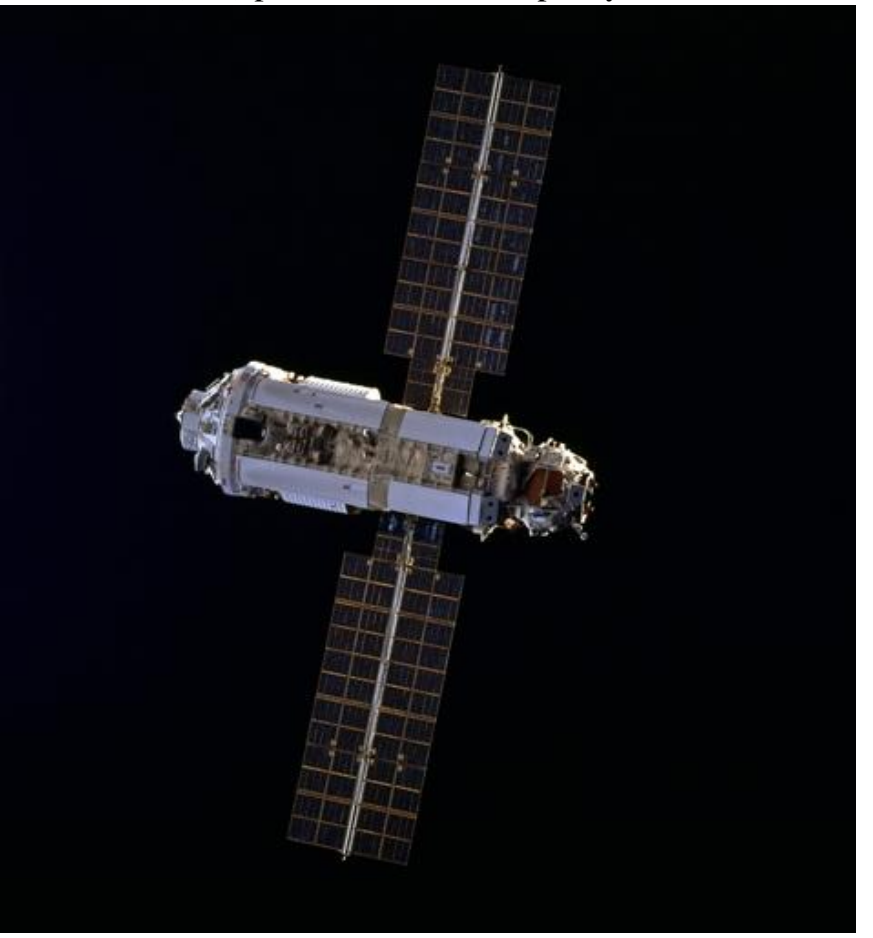

Figure 1 FGB in Free Flight contingency, a large amount of propellant, possibly in excess of the capacity of the Progress vehicles, would have to be consumed in a short period of time to safely 


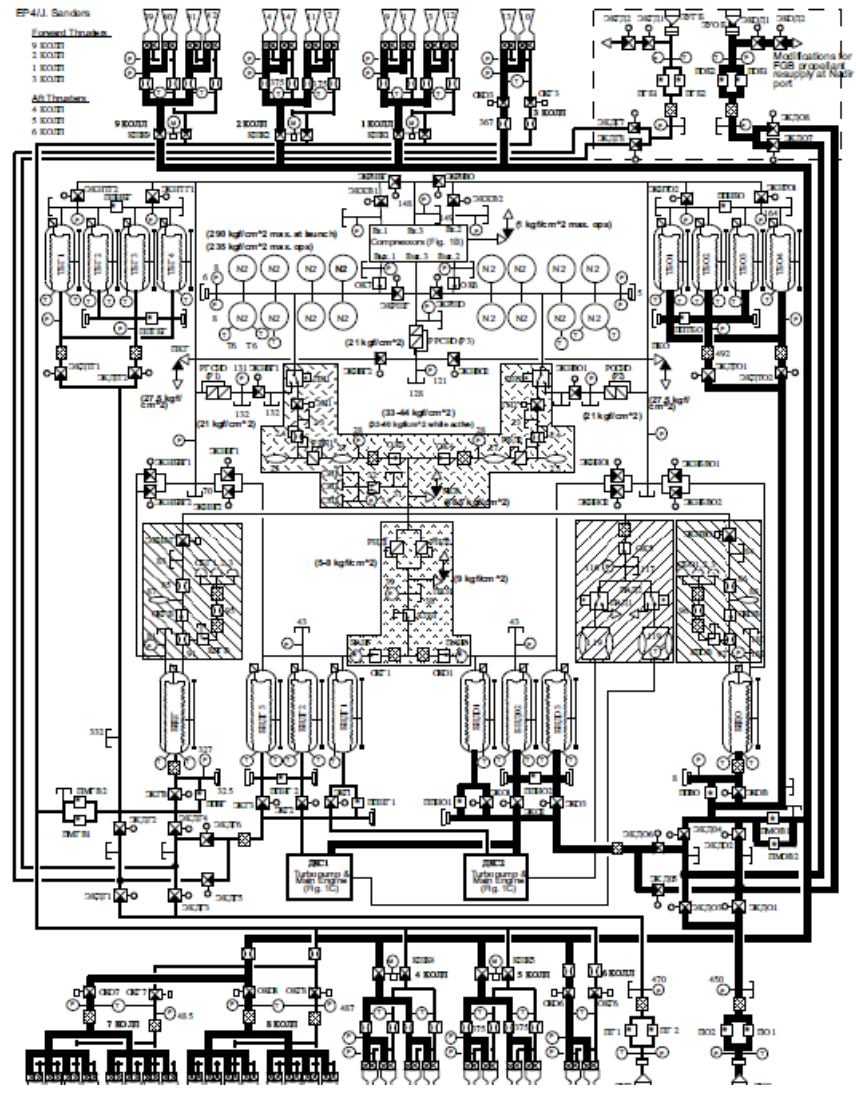

Figure 2 FGB Propulsion System

candidate components based on failure mode effects analysis, system level impacts, hazard analysis, etc. An overview of the system description and operations along with fault tolerance and safety provisions are presented. Tests and analyses performed, important findings and expert assessments are summarized. Although some of the propulsion system elements used in the FGB and SM have common design heritage, service life extension of the SM propulsion system involves additional considerations required for the continued operations of thrusters, avionics, etc. The SM life extension efforts will be presented in a separate paper.

\section{FGB Propulsion System}

The FGB (Zarya or "Sunrise"), the first ISS element launched, is an enhanced version of previously flown Mir science modules, Spektr and Priorda. It was built under a contract between Khrunichev Space Center and The Boeing Company and was financed by NASA. The FGB incorporates two docking interfaces that support propellant transfer, the aft docking port and the forward-nadir docking port. At a dry mass of approximately $2600 \mathrm{~kg}$, the FGB propulsion system consists of an intricate network of propellant tanks, pressurant tanks, compressor blocks and two distinct pressurization and feed system configurations; one for free flight and another for in-orbit operations after SM integration. In free flight, FGB relied on two turbopump-fed, regeneratively-cooled $417 \mathrm{kgf}$ Main Engines, twenty-four $40 \mathrm{kgf}$ thrusters and sixteen $1.3 \mathrm{kgf}$ deorbit the ISS. It would be extremely difficult, if not impossible, to ensure a safe and successful deorbit of the ISS without utilizing the FGB propellants. Taking this into consideration, the ISS Program authorized Boeing and Khrunichev to begin activities necessary to extend the FGB service life until 2028.

The objective was to evaluate the entire system, without testing every single component. Evaluating all the components and sub-elements through a rigorous test program would be an expensive proposition. The type of testing required for extending the service life depends on the design and criticality of the component, failure modes and failure mechanisms, life cycle margin provided by the original certification, operational and environmental stresses encountered, etc. When specific failure mechanism being considered and the underlying relationship of that mode to the stresses provided in the test can be correlated by supporting analysis, time and effort required for conducting life extension testing can be significantly reduced.

This paper describes the approach used for the service life extension of the FGB propulsion system. It outlines some of the techniques used for selective testing, by way of cherry picking

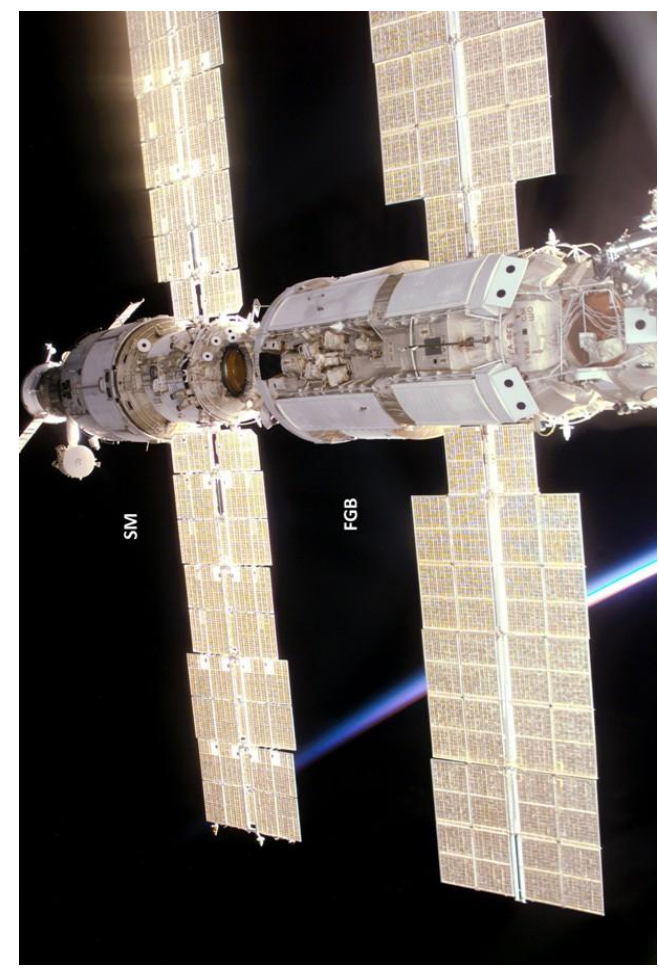

Figure 3 FGB Integrated with Service Module 
thrusters for orbital maneuvers and 3-axis attitude control ${ }^{2}$. Also prior to SM arrival, FGB Attitude Control System (ACS) thrusters were fed by tanks that were controlled with a pressure-switch based closed-loop pressurization scheme. After successful SM integration, the FGB Main Engines were permanently isolated by firing normally open pyrotechnic valves in the propellant and pressurant lines. The valves, switches and regulators responsible for the closed-loop pressurization of ACS propellant tanks were also isolated by firing the switching pyros, which in effect, disabled the software responsible for ACS firing. Latching solenoid valves and ball valves isolating the propellant supply to ACS thrusters have remained closed since then. Figure 1 shows FGB in free flight. Permanently isolated sections of the FGB propulsion system are denoted as hatched regions in Figure 2. ISS configuration after integrating the Service Module with the FGB is shown in Figure 3.

Control system for the FGB propulsion system consists of two independent sections; one dedicated to thruster activations in free flight and the other for pressurant and propellant management for ISS integrated operations. Motion Control System (MCS) responsible for thruster control was deactivated upon SM integration and the Onboard Computer System (OCS) responsible for propellant supply to and from FGB will remain operational until the end of ISS life.

\section{Service Life Extension}

Probability that a component with constant failure rate $\lambda$ will fail at or before time $t$ in the future can be expressed as

$$
F(t)=1-\lambda e^{-\lambda t}
$$

Reliability is the probability that the component will survive at least until time $t$ and is given by

$$
R(t)=\lambda e^{-\lambda t}
$$

A system comprises of many components with varying failure rates. Reliability of a system is the probability that it will perform its intended function under encountered operating conditions, for a specified period of time. As we are interested in finding out how reliable a system would be in the future, reliability expressed as a function of time provides valuable insight.

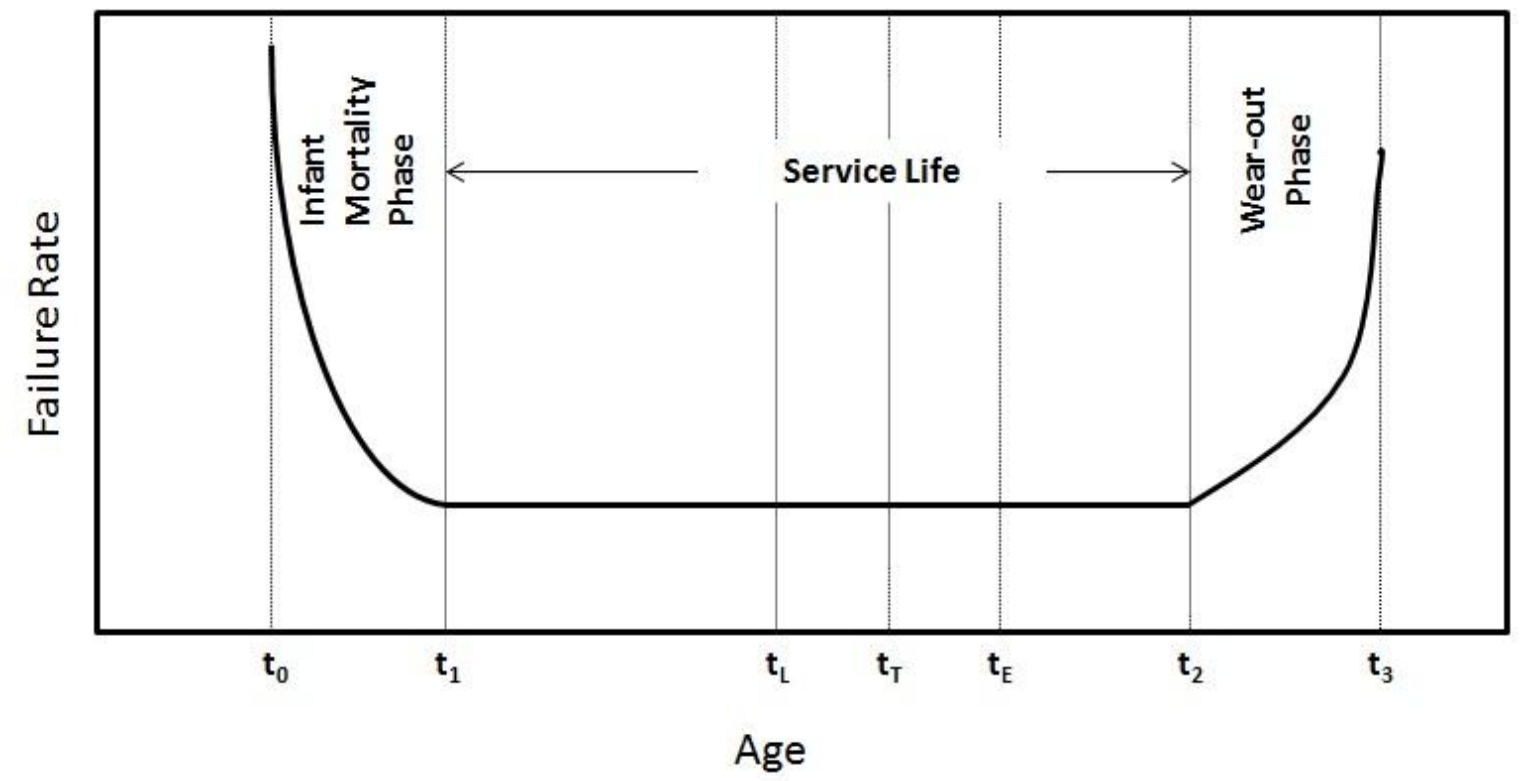

Figure 4 Bathtub Curve of Failure Rate

However, the component failure rates do not remain constant over the entire cycle life. In a hypothetical bathtub shaped failure rate curve shown in Figure 4, the failure rate, defined as the number of failures per unit time that a currently healthy component will suffer in a given future time interval, decreases during infant-mortality period, 
stays nearly constant during the service life and increases at the end when the design service life ends and wear-out phase begins ${ }^{3}$. The failure rate depends on various factors such as design complexity, current age of the component, operating conditions, severity of environmental stress factors, etc. Development, qualification and acceptance test processes provide rigorous screening of components to weed out imperfections that might otherwise cause infant mortality failures.

If sufficient samples are tested to failure, the failure time versus failure quantity can be analyzed statistically to develop a failure probability distribution function (PDF), a statistical model of the probability of failure versus time. Applying Weibull distributions proposed by Waloddi Weibull in $1937^{4}$, Defay defines variations in failure rate as a function of time ${ }^{5}$

$$
\lambda(t)=\frac{\beta}{\eta}\left(\frac{t_{b d}}{\eta}\right)^{\beta-1}
$$

where $\beta=$ shape factor of the Weibull PDF, $\eta=$ scale factor of the Weibull PDF and $t_{b d}$ is the time-tobreakdown. The parameter $\beta$, also known as Weibull slope varies with time to drive the evolution of failure rate. As seen in Figure 4, the failure rate decreases with time when $\beta<1$, stays constant when $\beta=1$ and increases with time when $\beta>1$.

Driven by cost and schedule constraints, however, spacecraft components are generally not tested in large numbers. Uncertainties in failure rate and remaining life estimates increase when fewer units are tested. To account for this, spacecraft operators prefer to limit useful operations to a period shorter than the maximum demonstrated service life of the weakest component. Running each component to its failure to determine the maximum possible service life of a system can become overly expensive and impractical. Spacecraft operators therefore, specify the required service life and an acceptable factor of safety (FOS). The designers use these requirements to limit the life test duration. Thus, assuming the service life of a spacecraft system begins at time $t_{l}$ in Figure 4 , life testing the components to demonstrate service life of $t_{T}$ would ensure the required FOS when the operational life is limited to $t_{L}$ such that

$$
F O S=\frac{\left(t_{T}-t_{1}\right)}{\left(t_{L}-t_{1}\right)}
$$

Midway through the service life span, when benefits justify the additional investment, supplementary life test may be performed to demonstrate the capability to safely extend the life to a time $t_{E}$ such that $t_{L}<t_{E}<t_{2}$.

\section{A. Selective Testing}

An innovative approach was required to ensure continued availability of the FGB propulsion system elements beyond their original certification period of fifteen years. Evaluating every component through a brute force test program would be a cost prohibitive and time consuming endeavor. FGB propulsion system components were designed and built decades ago. There were no representative ground test articles for some of the components. A 'test everything' approach would require manufacturing new test articles. With original manufacturers having gone out of business and with rapid changes that have taken place in materials, machines, manufacturing, and operator skills, it would be difficult to reproduce representative test articles in many cases. A pragmatic and well thought out approach was required to evaluate the entire system, without having to go through an elaborate test program.

FGB propulsion system consists of over 200 individual components broadly categorized under 30 groups based on their varying design, function and complexity. Along with 16 propellant tanks, 16 pressurant tanks and 42 thrusters, it makes use of 3 functionally redundant compressors, 14 check valves, 9 safety relief valves, 32 pyrotechnic valves, 7 pressure regulators and over 70 isolation valves of various kind. In addition, parts within some of these units may also be critical from a system performance and safety perspective. Depending on their operational criticality and safety implications, several components and their parts would possibly require dedicated life assessment.

A comprehensive survey was conducted to identify the components and parts that needed to be subjected to detailed investigation. First, a list of all the components used in the FGB propulsion system was generated, by categorizing the components as active or inactive. Components in the isolated sections that were no longer in service were listed under inactive category. 
Next, based on engineering judgment, failure modes of all the components, both active and inactive, were identified and qualitative rankings were assigned for probability of failure and severity of consequence. Items that ranked high on both likelihood of failure and operational/safety impacts were categorized as critical. Items that fell under active-critical group were first selected for life assessment. Some items were considered critical, even though they were no longer required for ISS operations. For instance, although the FGB Main Engines have been isolated and disabled, they were still considered critical since a small amount of propellant locked up between the two closed valves in the engine feed system posed a significant safety risk to ISS.

System level hazard analysis was performed next to identify available fault tolerance against ISS hazards. In this bottoms-up analysis, functional redundancy of each component was considered along with the effects of degraded performance if the primary hardware suffered a failure. Items providing adequate layers of fault tolerance constitute robust design and hence need not be subjected to same rigorous testing as the items lacking multiple levels of redundancy. It was recognized that testing selective components providing redundancy mitigates the system level risk. So, the components and parts that benefited from the fault tolerance provided by the rest of the system were categorized as non-critical.

The survey produced four categories of components: Active-Critical (AC), Active-Non Critical (AN), InactiveCritical (IC) and Inactive-Non Critical (IN). Barring IN, components in all other categories were selected for further investigation. As can be seen in Figure 5, number of potential candidates to be evaluated for service life extension was still significant. Embarking on a test program that included component level testing at this stage would still be beyond the cost and schedule constraints of this project. Further optimizations were sought to minimize the time and expenses without compromising the main objectives.

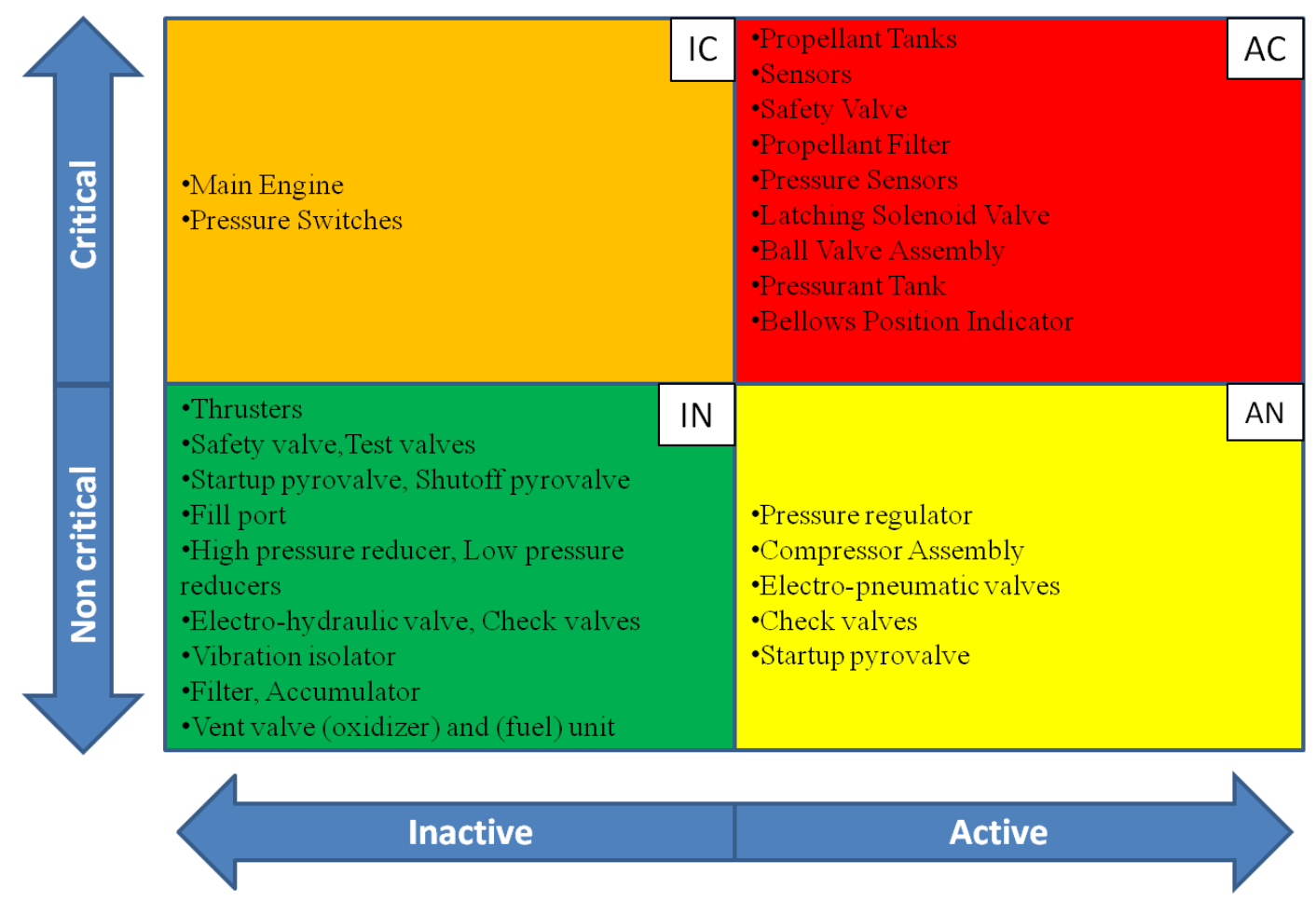

Figure 5 Component Survey and Categorization

\section{B. Optimization}

When FGB propulsion system was being assembled in the 1990s, components identical to the flight units were used to build a ground mockup, known as the D-Unit. Simulating the line dimensions and layouts in the propellant and pressurant segments of the flight unit FGB propulsion system, the D-Unit has been in use as a fleet leader on the ground. In order to minimize the number of independent test set ups, it was decided to use the D-Unit to apply flow and on/off cycles on multiple components simultaneously. Items covered under D-Unit testing included Propellant tanks, Safety valve, Solenoid valve, Ball valve unit, Pressure Indicator, Pressure Sensor and Fuel filter. 
Failure mode analysis, performed as part of the component survey described in Figure 5, was also used to identify the life limiting parts within individual components. With no accumulated cycle counts in orbit, efforts to extend the service life of components such as relief valves must focus on gradual degradation of material properties of soft goods (non metallic seats, seals, etc). Similarly, latching solenoid valves and ball valve assemblies used for isolating the FGB thrusters were not required to be certified for additional cycle life but required assessment of leakage integrity of their seals. Coupon level testing to characterize the performance of non metallic soft goods during accelerated aging in such cases would be the most cost efficient way to extract valuable data.

Certain components used in the propulsion system integration are designed to provide increased fault tolerance both in series and parallel redundant configurations. For instance, pressure regulation of propellant tanks is usually accomplished by a series redundant pressure regulator; if the primary regulator fails open, the tank pressure will continue to be regulated by the secondary regulator. However, if either primary or secondary regulator fails closed, the system loses its pressure regulation function. There are no credible failure-modes that cause a spring loaded mechanical regulator to fail closed. Thus, a series redundant pressure regulator is one-fault tolerant. An isolation valve in series with such a regulator arrangement provides two-fault tolerance against over-pressurization hazard. Safety relief valves provide additional fault tolerance over and above the required two-fault tolerance.

Parallel redundancy provided by replicating the series arrangement of isolation valve with pressure regulators and the safety relief valve, ensures necessary fault tolerance against loss of pressurization resulting from a closed failure of an isolation valve.

Even though they were categorized as AN, necessary fault tolerance provided by series-parallel redundant pressure regulators and electro-hydraulic/pneumatic valves meant that these units were not required to be included for a full up life extension testing. Similarly, benefiting from the three-for-one redundancy in compressor blocks, all the sub components and parts of the compressor system and the check valves in the pressurization system were treated as AN. Pressurant tanks were also categorized likewise, taking credit for the configuration featuring sixteen high pressure nitrogen bottles arranged in two functionally redundant, inter-connectable sections. All the AN elements were either assessed analytically or identified for life assessment by accelerated aging of representative soft goods.

\section{Accelerated Life Testing (ALT)}

The type of testing required for extending the service life depends on the design and criticality of the component, failure modes and failure mechanisms, life cycle margin provided by the original certification, operational and environmental stresses encountered, etc. When specific failure mechanism being considered and the underlying relationship of that mode to the stresses provided in the test can be correlated by supporting analysis, time and effort required for conducting life extension testing can be significantly reduced.

Exposure to corrosive propellants over long periods of time, for instance, lead to specific failure mechanisms in several components used in the propulsion system. Using Arrhenius model, which is tied to chemically dependent failure mechanisms such as corrosion or chemical reactions, it is possible to subject carefully selected test articles to ALT. Arrhenius model reflects the proportional relationship between time to failure of a component and the exponential of the inverse of absolute temperature acting on the component. To characterize the long term survivability of a component exposed to propellants at an average operating temperature of $T_{L}$, an acceleration factor $\alpha$ derived from Arrhenius model can be applied.

$$
\alpha=\frac{t_{T}}{t_{L}} \propto e^{\left[\frac{1}{T_{T}}-\frac{1}{T_{L}}\right]}
$$

where $t_{T}$ and $t_{L}$ are durations of accelerated test and intended service life respectively. $T_{T}$ and $T_{L}$ are the average temperatures in Kelvin to which the test article and the flight unit in service are exposed.

The acceleration factor is used to perform tests at higher stresses that allow direct correlation between the times to failure at a high test temperature to the temperatures to be expected in actual use. As long as the temperatures are such that new failure mechanisms are not introduced, this becomes a very useful method for testing to failure a relatively small sample of items for a much shorter amount of time ${ }^{6}$.

\section{Test and Analysis}

This section provides an overview of various tests and analyses performed, some sample results and conclusions drawn for the assessment of service life extension of the FGB Propulsion System. 


\section{A. Main Engine}

FGB is equipped with two Main Engines (also known as Correction and Docking Engines or CDEs). These turbo-pump fed, regeneratively cooled CDEs were used during the free flight period of the FGB for orbit insertion and large orbital translations. Designed to operate at a nominal inlet pressure of $5-6 \mathrm{kgf} / \mathrm{cm}^{2}(0.5-0.6 \mathrm{MPa})$ to generate a thrust of $417 \mathrm{kgf} \pm 16 \mathrm{kgf}(4089 \mathrm{~N} \pm 157 \mathrm{~N})$ at a chamber pressure of $41 \mathrm{kgf} / \mathrm{cm}^{2}(\sim 4.1 \mathrm{MPa})$, the CDE uses a pneumatic control system to activate the engine valves and to purge lines and turbopump cavities. The CDEs were qualified for 100 restarts and 3 years of on-orbit use. Two years after the FGB was launched, the CDEs were deactivated by permanently closing the normally open pyrovalves to isolate the propellant supply. Approximately 3.5 liter $\left(3.5 \times 10^{-3} \mathrm{~m}^{3}\right)$ each of UDMH and $\mathrm{N}_{2} \mathrm{O}_{4}$ at a pressure of up to $5 \mathrm{kgf} / \mathrm{cm}^{2}(\sim 0.5 \mathrm{MPa})$ remained trapped in the line segments between the pyrovalves and the turbopump inlet valves. The trapped propellants could not be vented from the main engine. The main engine operates nominally at a mixture ratio of $1.85 \pm 5 \%$. Operating the main engine outside of this range can lead to hazardous consequences including explosion. The venting operation can be performed only by sending a firing command to the main engine, which would open both the fuel and oxidizer valves simultaneously. This would result in mixing of the two propellants at an indeterminate mixture ratio which could lie outside of the nominal range. Two pyrotechnically actuated flow path switching valves were fired approximately a year later to permanently vent the main engine pneumatic control system to space, thereby precluding any further main engine operation. The FGB CDE inlet lines have been continuously exposed to propellants since about 1995. Effects of trapped propellants were characterized for the design service life until 2013. Additional testing was required to extend this certification.

\section{Test Article}

Thruster \#38 M, which was manufactured and test fired in 1986, was stored for 24 years in a heated warehouse. The unit was inspected, leak checked and readied for the life extension test.

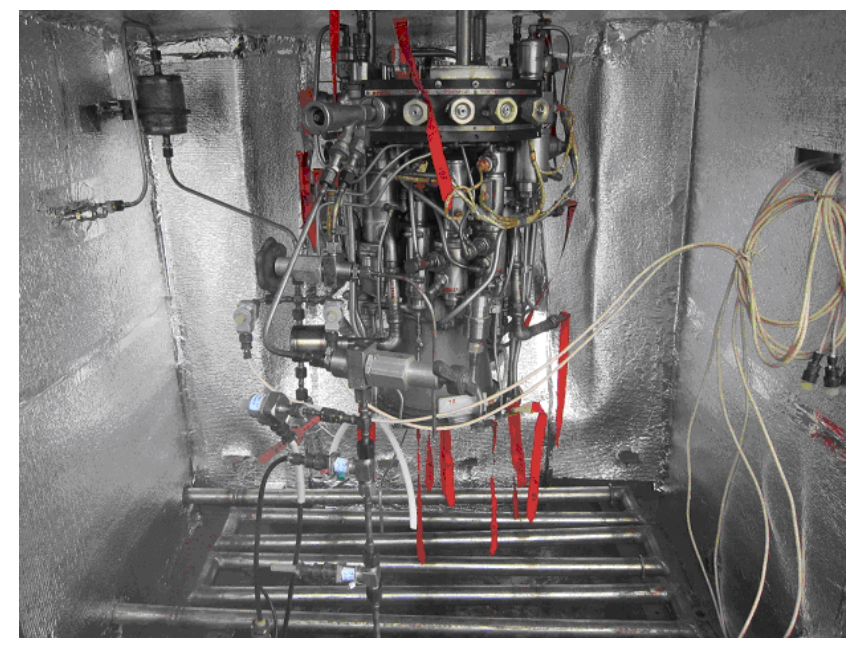

Figure 6 Main Engine Test Setup

\section{Accelerated Corrosion Test (ACT)}

The oxidizer line of main engine test article was evacuated and then filled with $\mathrm{N}_{2} \mathrm{O}_{4}$ and pressurized to 3 $\mathrm{kgf} / \mathrm{cm}^{2} .(\sim 0.3 \mathrm{MPa})$ Any propellant stored for longer periods of time typically exhibits deteriorated purity levels and therefore has to be purified before using for flight or ground test. The impurities present in the propellants trapped in FGB main engine maybe significantly different from the contaminant levels in $\mathrm{N}_{2} \mathrm{O}_{4}$ sample used for the aging test. To address this concern, $\mathrm{N}_{2} \mathrm{O}_{4}$ was drawn directly from the storage tank without purifying further to simulate the worst case conditions.

As shown in Figure 6, the engine was mounted in a thermal chamber and maintained at $50{ }^{\circ} \mathrm{C}(323 \mathrm{~K})$ for 225 days of ACT. The methodology utilizes an Arrhenius law approach, where the natural log of a reaction rate is proportional to inverse absolute temperature. By this method, for activation energies consistent with chemical reactions unaffected by diffusional limitations, increasing the temperature by $10^{\circ} \mathrm{C}$ will accelerate a chemical 
reaction rate by approximately two fold. If diffusion limitations exist, acceleration factor for thermal aging will be much reduced, and can be as low as 1.1 times per $10^{\circ} \mathrm{C}$ increase in temperature.

Temperature control devices, instrumentation and measurement systems were mounted and calibrated on the thermal chamber. During the test, power feed was provided continuously for the gas analysis system (Dräger Polytron 7000), the instrumentation and thermal control systems. The main engine was instrumented to measure the line pressure. At the end of 225 days of ACT, the main engine was leak tested using a gas analyzer (helium mass spectrometer). Propellant composition was monitored before and after the ACT. Following the leak check, the test article was sectioned to perform corrosion assessment of welds and parent material.

Figure 7 shows a sample view of the engine parts examined for defect analysis after the accelerated corrosion test. All the test results including the defect analysis, propellant composition test and the integrity of inlet and startup valves were nominal.
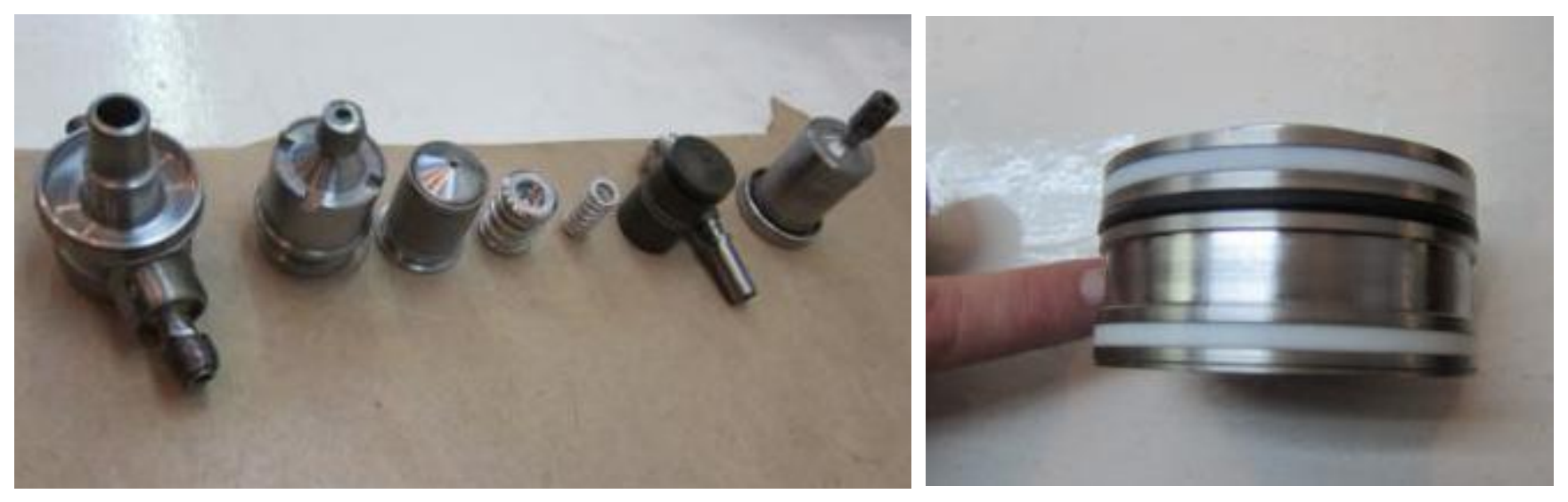

Figure 7 Defect Analysis

\section{B. Propellant Tank}

The FGB has 16 propellant tanks, 8 long tanks (3.528 m length, $0.48 \mathrm{~m}$ diameter, $88 \mathrm{~kg}$ dry mass), and 8 short tanks ( $2.923 \mathrm{~m}$ length, $0.48 \mathrm{~m}$ diameter, $75.6 \mathrm{~kg}$ dry mass). The FGB propellant tank provides propellant expulsion by utilizing a stainless steel bellows attached to a rigid hemispherical diaphragm. The rigid diaphragm incorporates 12 Teflon rollers to guide the bellows during cycle movement. The bellows construction includes a seam welded tube formed into a short bellows ( $\sim 6$ folds) and circumferential welded convolutes ( $\sim 40$ folds and $0.8 \mathrm{~mm}$ wall thickness). All welds are x-rayed. The bellows is approximately $2.4 \mathrm{~m}$ long when expanded and $0.5 \mathrm{~m}$ long when compressed.

Service life extension of a propellant tank required assessment of several aspects related to the construction and long term operation of the tank assembly. The bellows within each propellant tank was originally certified for 30 full cycles. When filling from 228 to 407 liters $\left(0.228\right.$ to $\left.0.407 \mathrm{~m}^{3}\right)$ and draining from 88 to 0 liters $\left(0.088\right.$ to $\left.0 \mathrm{~m}^{3}\right)$, the bellows material is subjected to the highest elastic deformations. When the bellows expands from 88 to 228 liters $\left(0.088\right.$ to $\left.0.228 \mathrm{~m}^{3}\right)$, the bellows undergoes negligible elastic deformation. One half-cycle can be defined as having been consumed each time the tank quantity either rises above or falls below a specifically determined tank level. For the long tanks, БВДГ/O and БНДГ/O 1-3, this level is 200 liters $\left(0.2 \mathrm{~m}^{3}\right)$. For the short tanks, ТБГ/O 1-4, this level is 150 liters $\left(0.15 \mathrm{~m}^{3}\right)$.

Pre-launch qualification of FGB propellant tanks involved 45 bellows cycles to include a safety factor of 1.5. As shown in Table 1 , additional 66 cycles $(42+24)$ were considered necessary to extend the service life certification until 2028.

Another concern in extending the service life of the propellant tank was related to the life of sensors within the tanks. Each tank consists of three Bellows Position Indicators (BPI) at the top of the tank, which are activated when the tank is full. Additionally, the propellant tank uses a bellows sensor, called a linear translation transducer (LTT) to gage propellant in the tank. The sensor measures bellows position with the help of a cable attached to the rigid hemispherical diaphragm and a shaft at the top of the tank. As the propellant is consumed, the bellows collapses toward the bottom pulling the cable with it. The bellows/rigid diaphragm position can be calculated by using a 
potentiometer to determine the length of the cable between the rigid diaphragm and the shaft. Applying required number of full cycles on representative tanks would address the cycle life issues for bellows as well as the sensors.

Table 1 Bellows Cycles

\begin{tabular}{|c|c|c|c|c|c|c|}
\hline $\begin{array}{c}\text { Start of } \\
\text { Operating } \\
\text { Period }\end{array}$ & $\begin{array}{c}\text { End of } \\
\text { Operating } \\
\text { Period }\end{array}$ & $\begin{array}{c}\text { Number } \\
\text { of Years }\end{array}$ & $\begin{array}{c}\text { Expected } \\
\text { Cycles } \\
\text { per year }\end{array}$ & $\begin{array}{c}\text { Expected } \\
\text { Cycles } \\
\text { over } \\
\text { period }\end{array}$ & $\begin{array}{c}\text { Safety } \\
\text { Factor }\end{array}$ & $\begin{array}{c}\text { Test } \\
\text { Cycles } \\
\text { Applied }\end{array}$ \\
\hline 1998 & 2013 & 15 & 2 & 30 & 1.5 & 45 \\
\hline 2013 & 2020 & 7 & 4 & 28 & 1.5 & 42 \\
\hline 2020 & 2028 & 8 & 2 & 16 & 1.5 & 24 \\
\hline \multicolumn{2}{|c|}{ Cumulative } & 30 & & 74 & 1.5 & 111 \\
\hline
\end{tabular}

An additional concern related to propellant tank recertification was that the cable/potentiometer device is guaranteed to work only if propellant vapor concentration in the tank ullage is $\leq 0.005 \mathrm{mg} / \mathrm{liter}\left(\leq 5 \mathrm{mg} / \mathrm{m}^{3}\right)$. Higher concentrations may cause intense corrosion both in the gage and other tank parts (like bearings, guides, cable, etc.). To address this risk, it was decided to apply additional 111 cycles on four sensor assemblies while subjecting them to accelerated corrosion testing.

Structural integrity of the propellant tank is another critical aspect to be addressed for extending its service life. The tank shell is made of an aluminum-magnesium alloy and the bellows and rigid diaphragm are made of stainless steel. A bimetallic weld joint is used to attach the bellows to the tank shell. The tank shell for the high pressure tanks is $\sim 2.5 \mathrm{~mm}$ thick and is $\sim 1.5 \mathrm{~mm}$ thick for the low pressure tanks. It was decided to perform a structural analysis to ascertain the structural integrity of the propellant tanks.

\section{Assessment for Propellant Tank Assembly}
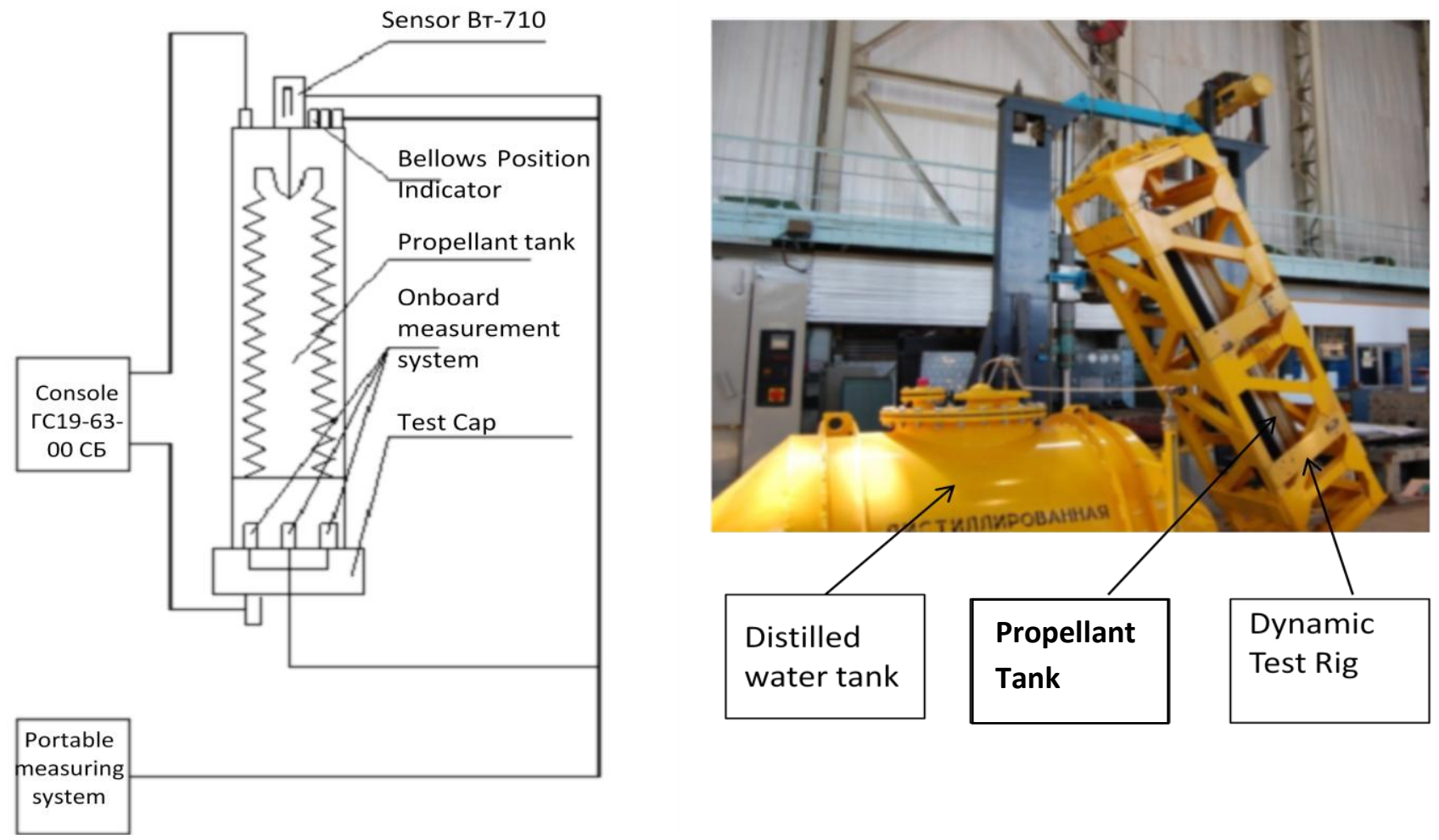

Figure 8 Propellant Tank Test Setup for Bellows Cycling (left) and Wet Vibration (right) 
Two short and two long propellant tanks were selected for carrying out bellows cycle life extension tests. They included two tanks from the D-Unit (described in a later Section), one standalone short tank and another tank removed from FGB-2. FGB-2 was built as a backup for ISS FGB (also known as FGB-1). D-Unit tanks were subjected to bellows cycle life testing as described above.

Figure 8 shows examples of test arrangements used for the propellant tank. Visual inspection, pressure check, leak check and sensor performance verification were performed at various stages of the sequence on the standalone tank. The tank was subjected to incoming inspection, transportation vibration testing on a truck, thermal cycling, vibration, shock test, cycle life test and defect analysis

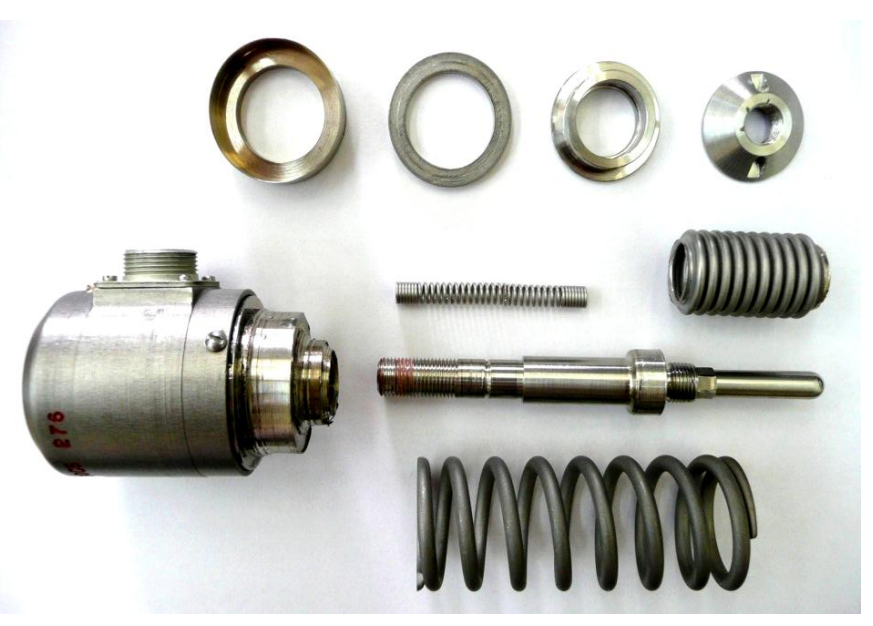

Figure 9 Defect Analysis of Bellows Position Indicator

The tank with its bellows and sensors withstood all the tests and met their performance specifications. All three Bellows Position Indicators (designated \#213, \#214 and \#215) were removed from the tank for further assessment. BPI \#213 underwent an additional 90 actuations at $27 \mathrm{~V}$ and $0.25 \mathrm{~A}$ by applying a cyclic load on the connector rod that actuates the limit switch. All three BPI units \#213, \#214 and \#215 were dismantled and subjected to defect analysis. As seen in Figure 9, the piece parts were found nominal without any chips, scuff marks or scratches.

Accelerated Corrosion Test (ACT) was performed on the LTT. In the case of the main engine, the test was performed on a line segment filled with liquid propellant (100\% concentration). Elevated temperature of $50^{\circ} \mathrm{C}(323 \mathrm{~K})$ was applied over 225 days to complete the accelerated aging test. In the case of LTT, by increasing the propellant concentration by 10 fold, the test duration was reduced further.

Original specification for allowable propellant concentration of $5 \mathrm{mg} / \mathrm{m}^{3}$ was derived by the designers based on their 1970's research on bellows technology.

This allows for sensor operation in spite of the worst case molecular diffusion of propellants that could take place through the thin membrane of stainless steel bellows. Original design specification required LTT to withstand exposure to $5 \mathrm{mg} / \mathrm{m}^{3}$ of propellant vapors for 15 years. Prior to FGB launch, accelerated aging test was performed to demonstrate this capability. Even though it is considered unlikely to have maximum concentration over the entire service life, current assessment is performed for the worst case. So far, there is no indication from available telemetry to suggest degraded performance of the sensor. Taking all available data including the life test assessment into account, it was concluded that there is no reason to increase the maximum concentration beyond the original specification of $5 \mathrm{mg} / \mathrm{m}^{3}$ for 30 years operation.

A total of 6 sensors were placed inside two sealed test chambers. Two units (\#504 and \#509) were mounted in the fuel (UDMH) chamber and the remaining four units (\#635, \#869, \#1252 and \#1253) in the oxidizer $\left(\mathrm{N}_{2} \mathrm{O}_{4}\right)$ chamber. Both UDMH and two of the $\mathrm{N}_{2} \mathrm{O}_{4}$ sensors (\#635 and \#869) were from long tanks (measurement range 0$2800 \mathrm{~mm}$ ) and the others were from short tanks (measurement range 0-1250 mm). All sensor units were manufactured to original FGB specifications and were cycled to 111 cycles prior to the aging test.

The purpose of the ACT was to assess the performance of LTT assuming the worst case exposure to propellant vapors for 30 years (from 1998 to 2028). The test chambers were filled with a mixture of nitrogen gas and propellant vapors at a propellant concentration of $50 \mathrm{mg} / \mathrm{m}^{3}$, absolute pressure of $110 \mathrm{kPa}(0.11 \mathrm{MPa})$, relative humidity of $65 \%$, and temperature of $50^{\circ} \mathrm{C}(323 \mathrm{~K})$ for the duration of the test. Flight like mounting arrangement and sensor operation were not simulated.

Test articles were removed intermittently from the chamber, decontaminated and inspected at discreet intervals representing 4 year increments starting from the year 2020. Cable movement data was recorded along with qualitative observations of discoloration and changes in sound during cable movement. Electrical parameters were monitored, but no changes were observed. Cable extension/retraction was performed manually, by taking care to simulate in-orbit conditions of linear motion, without imparting lateral forces.

All parameters were nominal (with some discoloration, as expected) after 89 days of aging test, representing 26 years of service life. However, three of the four oxidizer units (\#869, \#1252 and \#1253) failed after 105 days (30 years of life). The spring loaded sensor cable on the failed units extended nominally during the test but failed to 
retract completely and got stuck at $210 \mathrm{~mm}, 120 \mathrm{~mm}$ and $125 \mathrm{~mm}$ respectively. Change in sound was noticeable during the cable movement and these cables had excessive discoloration. The fourth unit did not get stuck, but had undergone discoloration and altered sound pattern, indicating that it could be on the verge of failure. Two of the failed units were new and the other had taken part in the bellows cycle life test, indicating that shelf life had no effect on the test results. The lubricant on the cable drum of all three sensors had turned into a gummy substance, likely from a reaction between the lubricant material and $\mathrm{N}_{2} \mathrm{O}_{4}$ vapor. The final cable tension force, change in output signals, and final output resistance were not checked, calibration specifications were not collected, and the primary error of each measuring channel was not determined, because these parameters require cable displacement over the measuring range. Efforts to derive a correlation between propellant concentration and sensor parameters were not successful. Since the sensors stayed static within the test chamber, there is no data to verify whether the degradation could have been less severe, if the cable movement was simulated to represent in-orbit conditions. The static condition simulates the worst case.

The test data suggests that the sensors may work nominally until 2024, but there is a risk of sensor cable getting stuck after this point. After 2024, FGB will be able to supply propellants nominally to SM and Progress. However, refueling of FGB tanks may not be possible.

In addition to a slew of tests performed on the propellant tank assembly, structural integrity of the propellant tank was analyzed by determining its crack growth resistance. For this analysis, updated finite element models (FEM) of the FGB propellant tank were developed, the stress-strain state of structures subjected to internal pressure was calculated, and structural crack growth resistance was analyzed according to NASGRO software Version 6.10. The details of this analysis will be presented in a separate paper.

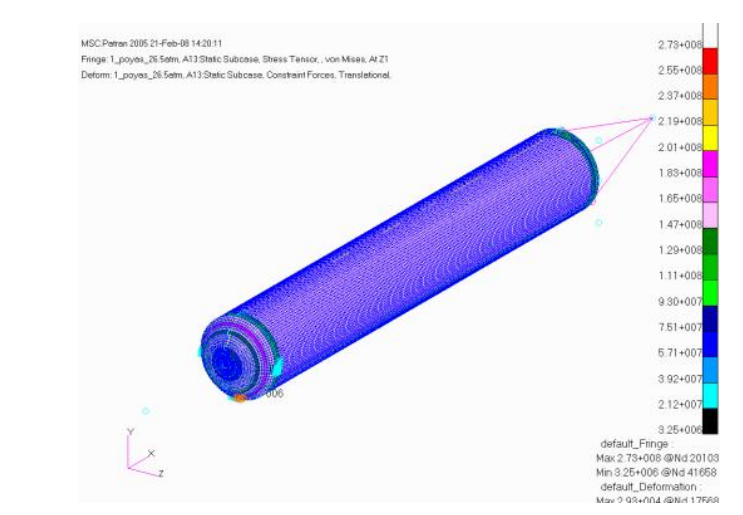

Figure 10 Stress intensity $(\mathrm{Pa})$ on the external surface of the Propellant Tank at 26.5 atm

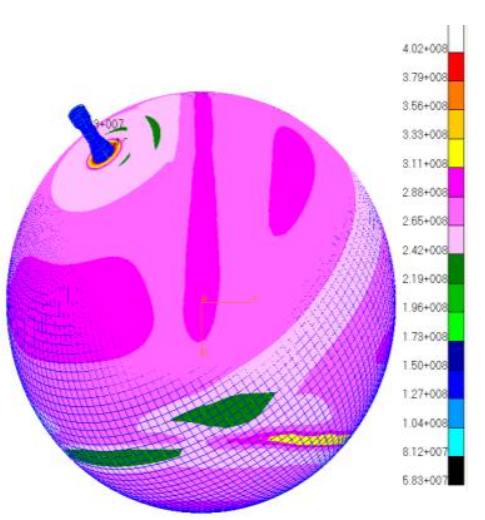

Figure 11 Internal surface stress according to Von Mises $(\mathrm{Pa})$ for Pressurant Tank at 200 atm

\section{Pressurant Tank}

Nitrogen gas, used as pressurant in the FGB propulsion system is stored in 16 high pressure tanks, arranged in two inter-connectable sections. The nitrogen tanks are 38 liter spherical tanks made of titanium $(5.5 \mathrm{~mm}$ wall thickness). All of the pressurant lines are made of stainless steel. Bimetallic weld joints are used to attach the tanks to the stainless steel feed lines. FGB was launched at a maximum ground fill pressure of $200 \mathrm{kgf} / \mathrm{cm}^{2}$ in its pressurant tanks. After propulsion system activation, the pressure dropped to approximately $160 \mathrm{kgf} / \mathrm{cm}^{2}$, ensuring that the tank maximum design pressure (MDP) of $200 \mathrm{kgf} / \mathrm{cm}^{2}$ is not exceeded even at the worst case temperature of $50^{\circ} \mathrm{C}$.

Although categorized as an 'Active-Critical' component (Figure 5), the pressurant tank was not subjected to a dedicated life extension test but was assessed for structural integrity using FEM analysis (Figure 11), which will be discussed more in detail in a separate paper.

Additionally, a nitrogen tank in the D-unit was used for pressurizing the propellant tank during bellows cycle life test. A total of 32 cycles of compressor usage was applied on the pressurant tanks, which was sufficient to perform all required bellows expansion/compression cycles in the D-Unit propellant tanks towards service life extension. Details on testing performed with the D-Unit components are discussed next. 


\section{Testing on the D-Unit}

The D-Unit was used to optimize the test program by performing an integrated test on several components listed in Table 2.

Table 2 Test Articles on the D-Unit

\begin{tabular}{|c|l|c|}
\hline$\#$ & Component & $\begin{array}{c}\text { Number of } \\
\text { units tested }\end{array}$ \\
\hline 1 & Safety valve & 1 \\
\hline 2 & Pressure indicator & 1 \\
\hline 3 & Pressure indicator & 1 \\
\hline 4 & Solenoid valve & 2 \\
\hline 5 & Ball valve unit & 1 \\
\hline 6 & Propellant tank & 2 \\
\hline 7 & Propellant filter & 1 \\
\hline
\end{tabular}

In addition to the components listed here, a total of 16 pressure sensors and pressure indicators were removed from the D-unit and were sent to the manufacturers for accelerated aging test. The D-unit line segments from which these units had been removed were end capped and leak tested. Figures 12 and 13 show the test arrangements used for D-Unit components.

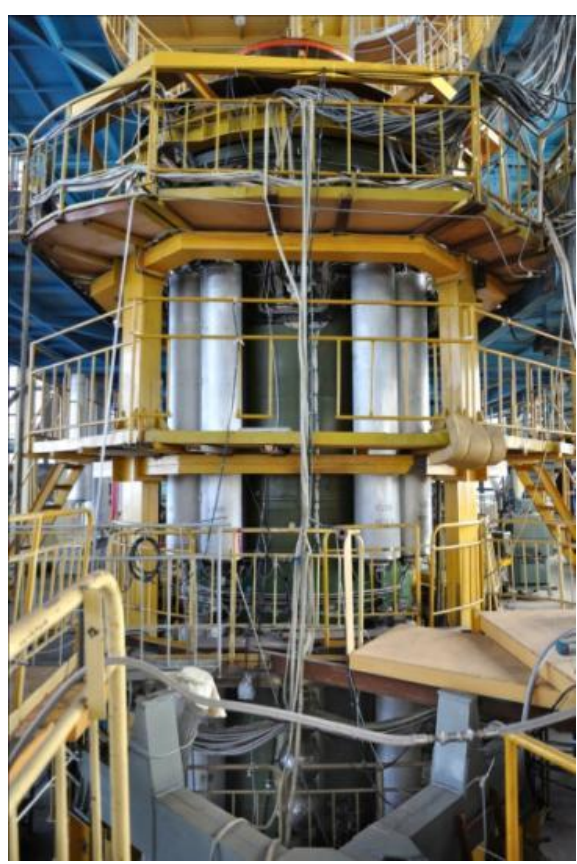

Figure 12 D-Unit Test Stand

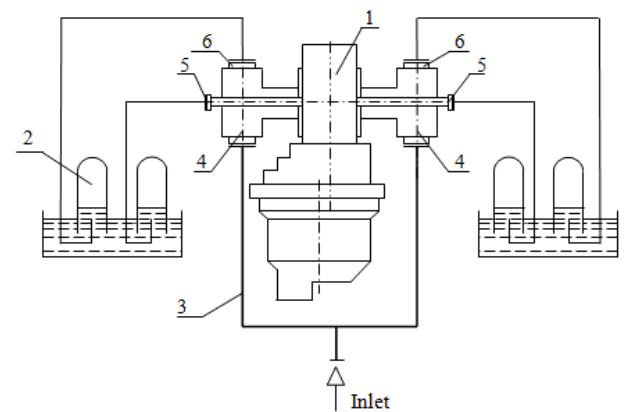

1 - ball valve unit $11 \Phi 77-6124-0 ; 2-$ measuring device; 3 - pipe $d_{y}=6 \mathrm{~mm}$; 4 -inlet fitting; 5 - vent fitting $11 \Phi 77-6124-4 ; 6$ - outlet fitting

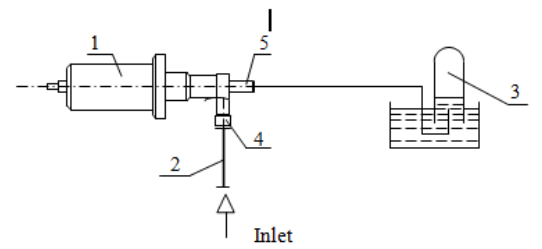

1 - safety valve $77 \mathrm{KM}-6312-0 ; 2-$ pipe $_{\mathrm{y}}=6 \mathrm{~mm} ; 3$ - measuring device; 4 - inlet fitting; 5 - outlet fitting

\section{Figure 13 Leak Test Setup}

Three bellows position indicators and one linear translation transducer were removed from one of the D-unit propellant tanks (separate from the 4 tanks identified for bellows cycle life testing described earlier) and were sent to the vendor for life extension testing. Required number of cycles was applied on Pressure sensor, pressure indicator, Nitrogen tank, Safety valve, Magnetic impulse valve and the Ball valve unit.

Pressure indicators (pressure switches) were tested for their actuation pressures over 32 pressure cycles. Set pressure in the pneumatic system lines was raised to $40 \mathrm{kgf} / \mathrm{cm}^{2}(\sim 4 \mathrm{MPa})$ and then decreased until the indicators actuated. Along with the 32 cycles on the pressurant tank, the safety relief valves were actuated 16 times by pressurizing the pneumatic section of the D-Unit to $27.5 \mathrm{kgf} / \mathrm{cm}^{2}(\sim 2.75 \mathrm{MPa})$. The propellant tanks remained unconnected during the tests and the bellows were not affected by the pressure release from the safety valves. The position of the bellows was verified to confirm that the shutoff valves were not leaking during the release of 
pneumatic pressure. A performance deviation was observed in the safety valve opening pressure. The valve opened at $26 \mathrm{kgf} / \mathrm{cm}^{2}(\sim 2.6 \mathrm{MPa})$, instead of its specification level of $27 \mathrm{kgf} / \mathrm{cm}^{2}(\sim 2,7 \mathrm{MPa})$. The deviation was considered minor and was not expected to impact the functionality.

The solenoid and ball valve units were subjected to $32 \mathrm{on} /$ off cycles. De-mineralized water was used to simulate propellant flow to and from the propellant tanks and the filter unit. Approximately 335 liters $\left(0.335 \mathrm{~m}^{3}\right)$ of water was allowed to flow from one tank to the other per cycle. Each cycle represented an expansion/compression cycle of the bellows during propellant transfer to/from the FGB tanks. These cycles also simulated propellant flow across the filter unit in forward/reverse directions. In their role as fleet leader components, the D-unit tanks had already accumulated 28 cycles. Remaining 83 cycles were applied to accumulate a total of 111 cycles required (per Table 2) for the service life extension until 2028. Figure 14 shows examples of bellows cycles applied on the D-Unit tanks. Functional verification and leak test following the cycle life test yielded nominal results for all the components.
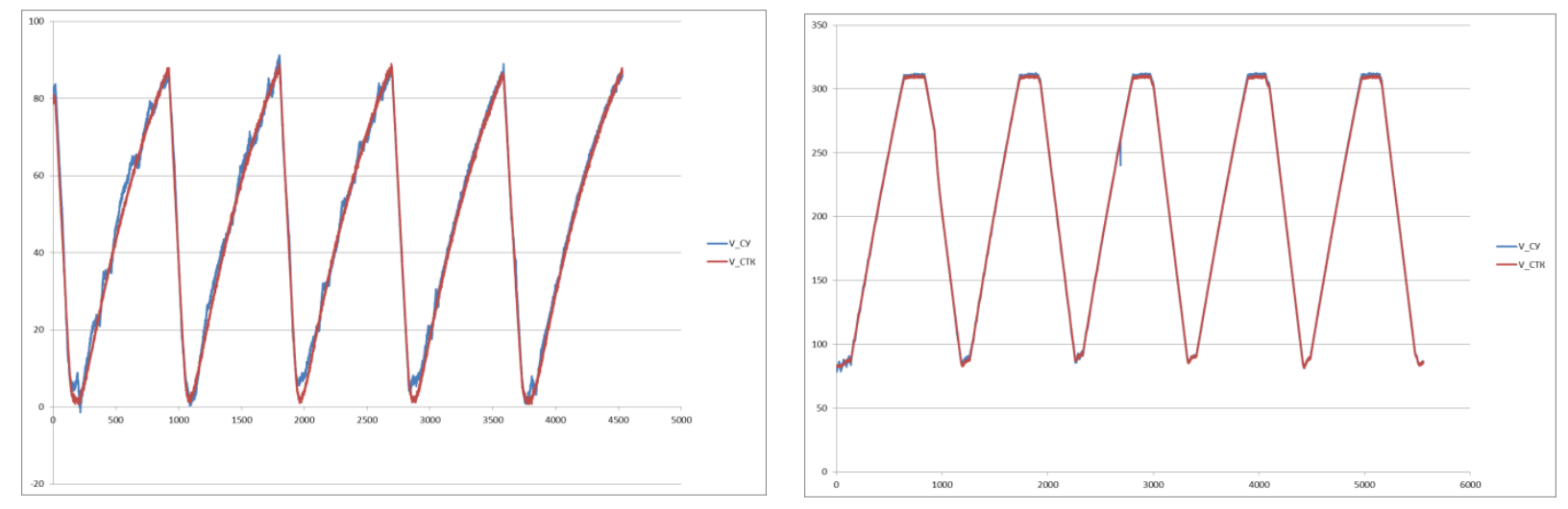

Figure 14 Change in propellant tank volume with bellows starting at the bottom (left) and the top (right)

The ball valve unit, the safety valve and the filter were removed from the D-Unit and subjected to accelerated aging by heating to and maintaining at $343 \mathrm{~K}$ for 7 days at a time for 8 times. After each 7 day hold period in the thermal chamber, the units were checked for leaks, specifically between the ball valve's outlet shaft and rubber Orings, at the seal between the ball and insert, between the safety valve seat and insert and in the propellant filter housing. All the units showed nominal performance. Defect analysis at the end of the accelerated aging revealed no defects.

\section{E. Compressor}

The FGB propulsion system compressor unit is designed to transfer nitrogen from propulsion system propellant tank gas volumes into high pressure pressurant tanks. The compressor unit is designed as a leak-tight container that houses three compressors, gas distribution equipment (valves, pressure reducers, calibrated orifices, etc.), and a gas-

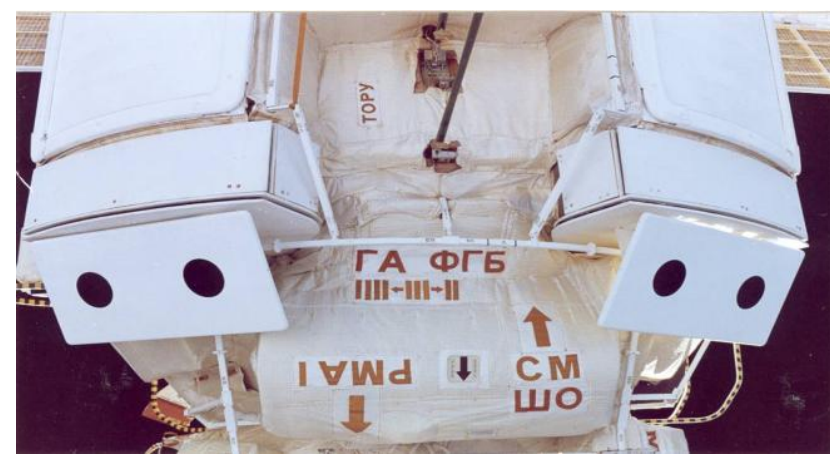

Figure 15 FGB Compressor Assembly under MMOD Shielding liquid heat exchanger. Nitrogen gas at 0.65 to 1.3 $\mathrm{kgf} / \mathrm{cm}^{2}$ (0.065 to $\left.0.13 \mathrm{MPa}\right)$ within the container helps the convective thermal control of the pneumatic supply units during operation. Fans in the pneumatic supply unit circulate gas through the gas-liquid heat exchanger, which is connected to the thermal control system of the FGB.

The compressor unit is located outside the habitation area, on the FGB exterior, and for this reason is not subject to routine inspection and repair by the crew during on-orbit operation. This circumstance required the development of a highly reliable pneumatic/hydraulic schematic for the compressor unit, which consists of three independent loops that, in turn, consist of identical components.

14

American Institute of Aeronautics and Astronautics 
Each loop is capable of performing a given function, successively transferring pressurization system nitrogen from propulsion system propellant tanks to high pressure tanks. Since the compressor unit pneumatic supply devices reliably operate at atmospheric pressure, they are located in a pressure-tight container in which a positive pressure is maintained.

Each compressor unit loop is composed of two primary lines: a suction line for nitrogen gas from propulsion system propellant unit ullage, and a gas discharge line to propulsion system high-pressure tanks. The functional components of each suction line are: a pressure reducer, a safety valve, a pressure indicator, and two fine-mesh gas filters, one of which is installed at the line inlet; the other, at the inlet to the pneumatic supply unit. The gas discharge line is equipped with two check valves installed sequentially. The gas pressure in the compressor loop is recorded by a telemetry pressure sensor. The principal element of the compressor unit pneumatic/hydraulic circuit is the pneumatic supply unit which is a single unit that contains a diaphragm-type two-stage compressor with a hydraulic drive, a receiver, and fans.

The metal diaphragms, rigidly fixed in a housing, oscillate between two plate surfaces that limit their motion in response to the pressure exerted by the working fluid. The fluid pressure is created by the reciprocal motion of the pistons driven by an electric motor through a single-stage planetary reducing gear unit. As the piston moves to top dead center, nitrogen gas is drawn into the volume enclosed by the diaphragm of the compressor's first stage. As the piston reverses direction, the diaphragm flexes in response to the pressure from the working liquid, compressing the gas and injecting it into the compressor's second stage. A similar cycle of operation occurs in the compressor's second stage. The nitrogen gas pressure in the compressor's first stage increases from 1 to $30 \mathrm{kgf} / \mathrm{cm}^{2}(0.1$ to 3 $\mathrm{MPa}$ ); and from 30 to $250 \mathrm{kgf} / \mathrm{cm}^{2}$ (3 to $25 \mathrm{MPa}$ ) in the second stage.

During the FGB flight, in orbit 18924 on 14 March 2002, one of the three compressors had failed to start. Ground testing had shown that a compressor might need a longer start pulse, if its piston gets positioned at its dead point. Troubleshooting performed in July of 2002 revealed that the compressor operates as expected until the pressure in the high pressure nitrogen tanks reaches $102 \mathrm{kgf} / \mathrm{cm}^{2}(\sim 10.2 \mathrm{MPa})$. The compressor capacity drops significantly at higher pressures, which implies that the likely cause is a failure of one of the check valves in the compressor unit. FGB operations continue nominally on the remaining two healthy compressors. As the compressor is categorized under 'Active-Non Critical' elements (Figure 5), no further assessments were considered necessary to ensure guaranteed performance of all compressors, meeting their maximum discharge pressure specifications. The following section highlights some of the tasks performed to extend the service life of the compressor unit.

Compressor Unit Test and Analysis

Standalone testing of the compressor unit consisted of a complete physical simulation of all compressor unit operating conditions except zero gravity. Work was carried out on an actual compressor unit, manufactured according to the same design specifications as the compressor unit flight article. Gas operating media at flight like temperatures and pressures were used during tests, with a $100 \%$ hold of all time and electrical parameters.

Integrated testing of the compressor unit was carried out on the integrated electrical test stand of the Mir orbital station. The compressor unit operated for 15 years on Mir as part of the flight article, fully supporting the propellant transfer operations of the integrated propulsion system.

During the manufacturing stage of compressor unit pneumatic/hydraulic system assemblies, standalone testing was performed, including using up their service lives for number of actuations. Analysis of the standalone test data showed that the scope of testing greatly exceeded the life requirement. All compressor unit assemblies and units are located under thermal insulation, and operating temperatures in the compressor unit installation area do not exceed the temperature limits of $-10^{\circ} \mathrm{C}$ to $30^{\circ} \mathrm{C}(263 \mathrm{~K}$ to $303 \mathrm{~K})$ over $90 \%$ of the time. Also, as of this writing, the pneumatic supply devices within the FGB compressor units have accumulated less than $22 \%$ of their certified operational lives. Projected usage until 2028 does not exceed the current certification levels. No additional cycle life extension tests were

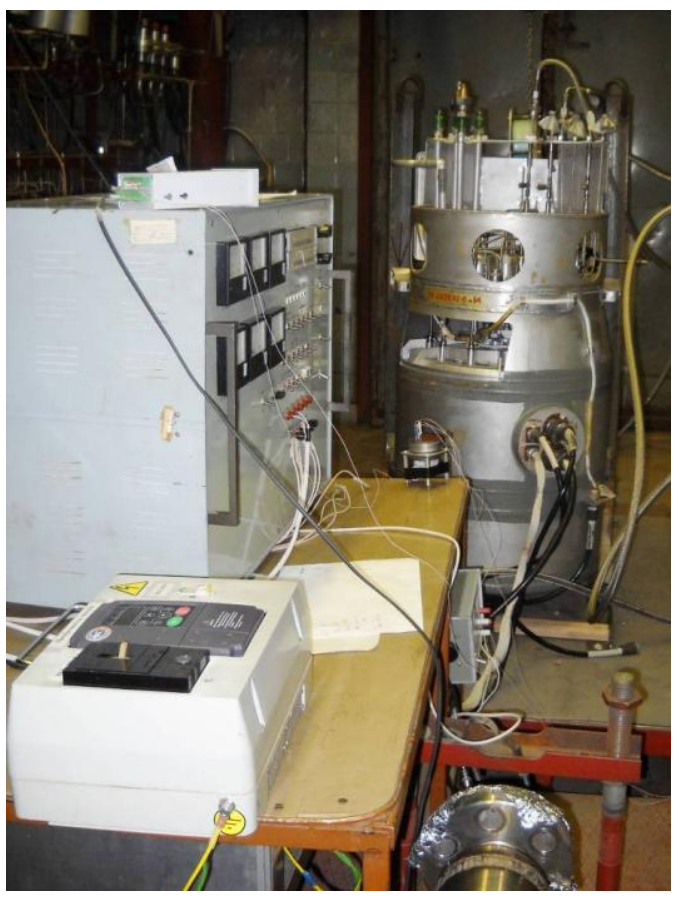

Figure 16 Compressor Test Setup considered necessary to confirm functionality until 2028. 
Critical elements within the compressor unit were analyzed for assessing the constraints, if any, on their operating lives. The operating life of the gas-liquid heat exchanger is constrained by the duration it is in contact with the Triol coolant. Accelerated aging test was performed with FGB thermal control system metals exposed to coolants polymethyl siloxane $\Pi \mathrm{MC}-1.5 \mathrm{p}$ and Triol, to confirm nominal operation of the heat exchanger unit until 2028.

Accelerated aging test on rubber seals was performed at elevated temperature to verify the extended life capabilities of pressure reducers, check valves, safety valves, two-position electro-pneumatic valve, and the safety valve. Analysis performed on various rubber types confirmed that the seals would retain their functionality until 2028.

During nominal compressor operation, the operating medium is high-purity nitrogen with a dew point not exceeding $-65^{\circ} \mathrm{C}(208 \mathrm{~K})$, filtered to a purity finer than $5 \mu \mathrm{m}$. No propellant vapors may be present in the nitrogen, which is assured by the schematics and design of the propulsion system. It is only possible for propellant vapors to mix with nitrogen in the event of a bellows leak in the propellant tank, which is an off-nominal situation.

The propellant vapor concentration level at which the compressor unit retains its functionality without constraint on operating time was not included in the life extension assessment, since the failure mode (bellows leak) which would introduce propellant vapors was already addressed by the propellant tank assessment.

However, some work to determine the propellant vapor concentration at which the compressor performance degrades was performed in the year 2000. A mixture of nitrogen and propellant vapors was supplied to the compressor unit inlet line on test stand ЭУ500; the mixture was allowed to be in contact with all line components: P1, СДН1, ПРК1, ДКН1, ДКВ1, КО1, КО6, and the pipelines. It was observed that the compressor performance did not degrade after exposure to propellant concentrations ranging from $0.074 \mathrm{mg} / \mathrm{m}^{3}$ to $3.84 \mathrm{mg} / \mathrm{m}^{3}$ for $1-3 \mathrm{hours}$ at a time over a test campaign of 20 day period.

Exposure to specification maximum limit of $5 \mathrm{mg} / \mathrm{m}^{3}$ of propellant vapor over 26-30 years is a concern that was studied as part of the propellant tank assessment. Causes leading to such failure modes are not considered to affect the compressor performance. A concentration of $5 \mathrm{mg} / \mathrm{m}^{3}$ in a propellant tank will result in a much smaller value distributed across the nitrogen section of FGB. Therefore, no changes were recommended with respect to the compressor operating procedures.

\section{F. Soft Goods}

Several of the 'Active-Non Critical' elements identified in Figure 5 were subjected to life assessment by accelerated aging of representative soft goods. Rubber seals and O-rings were characterized in their non-deformed and deformed states during storage and operational conditions. Test conditions were derived from computer algorithms predicting operational endurance of elastomeric materials and design lives of rubber components based on a set of mathematical, statistical and probabilistic models. Representative test coupons were placed in a thermal chamber at $70{ }^{\circ} \mathrm{C}(343 \mathrm{~K})$ for 30 days. Clamps were used during aging of rubber samples in a deformed state. Measurements were taken on days 3, 7, 14, 21, and 30. In the final stage of testing, the contact stress relaxation was determined using the axial compression relaxation instrument. Elevated pressure test took place in special containers. Relative residual compression deformation, stress relaxation, static/equilibrium compression modulus, sealing capability, and strength/relative strain upon failure were recorded. Isoprene-based rubber samples were additionally tested by indentation.

The results demonstrated a sufficient retention of the yield/elasticity properties of the material, constant elastic modulus, and a decreasing relaxation constant. Analysis of the test data confirmed feasibility of extending the service life of rubber sealing components by 23 years (overall guaranteed storage and operational life of 25 years, and storage and operational life in constituent assemblies of 24 years). For rubber sealing components (rubber/metal valves) made of rubber 51-1448, it is feasible to increase the operational life to 25 years at an operating temperature range of $-10^{\circ} \mathrm{C}$ to $30^{\circ} \mathrm{C}(263 \mathrm{~K}$ to $303 \mathrm{~K})$ and to 20 years at $-10^{\circ} \mathrm{C}$ to $50^{\circ} \mathrm{C}(263 \mathrm{~K}$ to $323 \mathrm{~K})$. With exposure to elevated nitrogen pressures (with a pressure drop from 22.5 to $9.0 \mathrm{MPa}$ ), the operational life is set at 23 years, with an overall guaranteed storage and operational life of 25 years, only for dual rubber/metal valves operating consecutively (redundant for failure of valves operating at maximum pressure). 


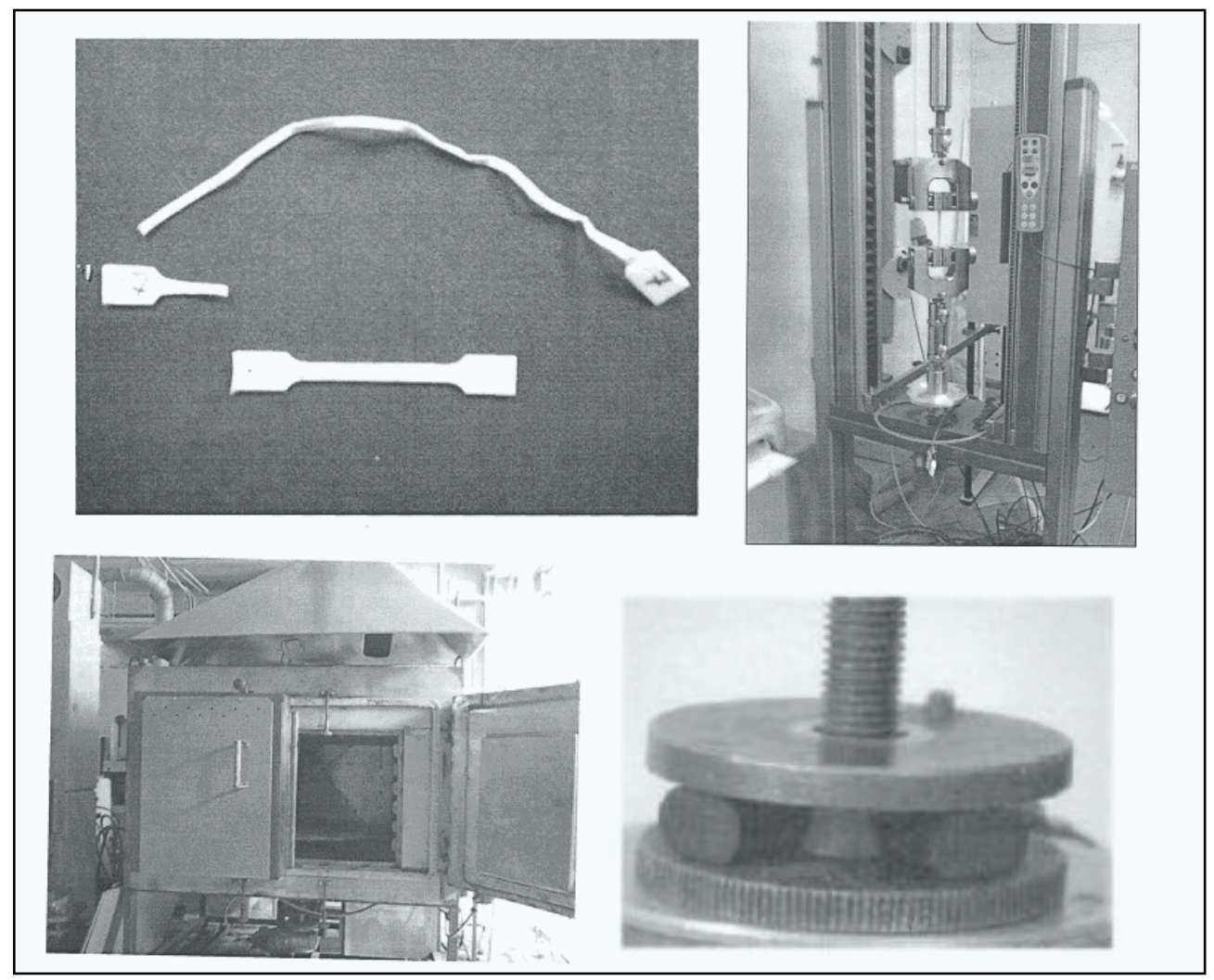

Figure 17 Soft Goods Testing

Fluoro-plastic sealing components in the fittings and assemblies of FGB propulsion system valves were also assessed using similar methods. Two types of Fluoroplast- 4 coupons underwent accelerated thermal aging testing: Pre and post aging strain and strength properties were determined by using a hydraulic press before and after subjecting $80 \times 5 \times 2 \mathrm{~mm}$ scoop-shaped strips to accelerated aging tests in a thermal chamber. For the accelerated thermal aging of polymer samples, a heat chamber was used with a maximum allowable error of $+2^{\circ} \mathrm{C}$ and a maximum allowable operating temperature differential of $+2{ }^{\circ} \mathrm{C}$. Analysis of the test data confirmed feasibility of extending the service life of all sealing components by 23 years (overall guaranteed storage and operational life of 25 years).

\section{Conclusions}

As part of the overarching goal to extend the service life of the ISS, systematic assessments have been performed for all the critical elements across multiple subsystems spread over different modules built by the U.S. and various international partners. Modules and vehicles responsible for propellant storage, supply, resupply and thruster operations are part of the Russian Segment. The FGB is the first element of the ISS, built in Russia under a U.S. contract.

The authors have discussed the efforts undertaken to systematically identify the life limiting components and to devise and execute a comprehensive, multipronged test and analysis campaign for extending the service life of the FGB propulsion system. Based on a series of tests and analyses performed at various test facilities and laboratories involving multiple private and public sector organizations and academic institutions across Russia, it has been concluded that the service life of nearly all the components within the FGB propulsion system can be safely extended for nominal operations until 2028. A notable exception is the LTT, operational life for which has been currently limited to 2024, due to a very low probability failure mode. NASA considers this low likelihood risk to be small enough to continue nominal operations until 2028. 


\section{Acknowledgements}

The authors would like to express their gratitude to the test teams at Khrunichev Space Center, RSC-Energia and other agencies, for diligently carrying out the tests and analyses and for being accommodative in making changes to the life extension protocols during the assessment process, as directed by the NASA customer. The authors would also like to thank the International Space Station Program for funding these extensive studies.

\section{References}

\footnotetext{
${ }^{1}$ Martin, M., Swanson, R., Kamath, U., Hernandez, F., and Spencer, V., "On-Orbit Propulsion System Performance of ISS Visiting Vehicles", AIAA, AIAA 2014-3590, Cleveland, OH, Jul. 2014

${ }^{2}$ Karakulko, W., Russell, S., Sanders, G.B., Spencer, V., "Russian Propulsion and Propellant Resupply Systems for the ISS", NASA, JSC-27979 Rev. F, Houston, TX, Mar. 2010.

${ }^{3}$ Koren, I., and Krishna, C., "Fault-Tolerant Systems," ISBN: 0-12-088525-5, Morgan Kaufmann, Jul. 2010

${ }^{4}$ Weibull, W., "A Statistical Theory of the Strength of Materials”, Ingeniörsvetenskapsakademiens Handlingar Nr 151, 1939, Generalstabens Litografiska Anstalts Förlag, Stockholm.

${ }^{5}$ Defay, E., "Ferroelectric Dielectrics Integrated on Silicon,” ISBN: 978-1-848-21313-5, John Wiley \& Sons, Oct. 2011

${ }^{6}$ Raheja, D., Gullo, L., “Design for Reliability,” ISBN: 978-0-470-48675-7, John Wiley \& Sons, Aug. 2012
} 